\title{
Non-utilization of hearts and lungs after consent for donation: a Canadian multicentre study
}

\author{
[La non-utilisation des caurs et des poumons d'adultes consentant au don \\ d'organes : une étude multicentrique canadienne ]
}

Karen Hornby BScN, ${ }^{*}$ Heather Ross MD FRCP, $†$ Shaf Keshavjee MD FRCS, $\ddagger$ Vivek Rao MD FrCs, $†$ Sam D. Shemie MDS

Purpose: To identify reasons why hearts and lungs from consented adult organ donors are not transplanted and identify changes in practice aimed at increasing their utilization rates. A greater potential may exist in Canada to improve utilization rates for hearts and lungs given their comparatively suboptimal rates (kidneys $85 \%$, livers $84 \%$, hearts $35 \%$ and lungs $23 \%$ reported in 200I).

Methods: Four Canadian organ procurement organizations participated. All adult organ donation cases for the calendar year 2002 were reviewed and included if consent for organ donation was obtained. An organ donation framework was established to highlight key areas where organs are lost from the transplantation stream. Organ donor cases were analyzed through this framework.

Results: A utilization rate of $39 \%$ (42/I07) for heart and $28 \%$ (29/105) for lung donors was found, comparable to Canadian and international rates. Organ function was the most frequently cited reason for non-utilization, followed by donor characteristics and logistical issues. Suggestions for alternate management, potentially resulting in organ utilization, were made in 20 of 65 (31\%) hearts and 28 of 156 (18\%) lungs. Variable practices, around consent for individual organs and offering of organs consented, remained significant barriers to successful transplantation.

Conclusion: Target areas for changes in practice included consenting and offering of all organs. Management of "marginal" organs should include resuscitation and reevaluation thus allowing potential organ rescue and utilization. Although there is considerable pressure to increase organs for transplantation, any such mechanism will not be judged successful unless recipient graft survival rates remain acceptable.
Objectif: Déterminer pourquoi des cœurs et des poumons de donneurs d'organes adultes consentants ne sont pas transplantés et présenter les changements de pratique envisagés pour accroître leur taux d'utilisation. Au Canada, le taux d'utilisation sous-optimal comparatif des cœurs et des poumons pourrait être meilleur : le rein, $85 \%$; le foie, $84 \%$; le cœur, $35 \%$ et le poumon, $23 \%$ en 2001 .

Méthode : Quatre services d'approvisionnement en organes ont participé à l'étude. Tous les cas adultes de don d'organes de 2002 ont été revus et inclus s'ils comportaient l'obtention d'un consentement. Une grille d'analyse du don d'organe a été établie pour reconnaître les situations où les organes échappent au circuit de la transplantation. Les cas des donneurs ont été analysés.

Résultats : Un taux d'utilisation de donneurs de $39 \%$ (42/107) pour le cœur et de $28 \%$ (29/105) pour le poumon a été trouvé, taux comparable aux taux canadien et international. Un problème organique fonctionnel était cité le plus souvent pour la non-utilisation, puis les caractéristiques du donneur et des questions logistiques. Une gestion différente a été suggérée, pouvant permettre l'utilisation de l'organe, pour 20 des 65 (3I \%) cœurs et 28 des 156 (I8\%) poumons. Des pratiques variables, sur le consentement au don d'organe spécifique et l'offre d'organes consentie, demeuraient des barrières significatives au succès de la transplantation.

Conclusion: Les changements de pratique ciblés touchent le consentement et l'offre reliés à tous les organes. Le traitement d'organes "marginaux» devrait inclure la réanimation et la réévaluation pour permettre le sauvetage de l'organe et son utilisation. Malgré l'immense pression pour augmenter le nombre d'organes transplantés, tout mécanisme ne sera jugé fructueux que si le taux de survie des greffons chez le receveur demeure acceptable.

From the Division of Critical Care, ${ }^{*}$ Pediatric Critical Care, $\$$ Montreal Children’s Hospital, McGill University Health Centre, Montreal, Quebec; and the Cardiac Transplant Program, $†$ Toronto Lung Transplant Program, $\ddagger$ University Health Network, Toronto, Ontario, Canada.

Address correspondence to: Dr. Heather Ross, NCSB 11C-1203, 585 University Ave, Toronto, Ontario M5G 2N2, Canada. E-mail: heather.ross@uhn.on.ca

We gratefully acknowledge the financial support provided by the Canadian Council for Donation and Transplantation enabling this study and the resulting manuscript.

Accepted for publication August 10, 2005.

Revision accepted September 16, 2005. 
U TILIZATION rates, the frequency with which organs are retrieved from a given donor and transplanted into a recipient, differ greatly depending on the type of cadaveric organ. Factors such as age, size and geographic location of the deceased donor may dictate the likelihood of retrieving viable organs. In 2001 the Canadian Organ Replacement Register (CORR) reported that $85 \%$ of kidneys, $84 \%$ of livers, $35 \%$ of hearts and $23 \%$ of lungs were utilized from deceased donors. ${ }^{1}$ Given the high utilization rates for livers and kidneys $(\sim 85 \%)$ vs the suboptimal rates for hearts and lungs, it was hypothesized that the potential exists in Canada to improve transplantation rates by improving utilization rates for hearts and lungs. The Donation Committee of the Canadian Council for Donation and Transplantation commissioned this study to determine: 1) reasons why hearts and lungs that have been consented for donation do not achieve transplantation; and 2) to identify target areas where changes in practice may lead to increased utilization rates of hearts and lungs.

\section{Methods}

Four organ procurement organizations (OPOs) from across Canada were invited to participate in this study. All of the organ donor case files (age $\geq 18 \mathrm{yr}$ ) for the calendar year 2002 were reviewed at each site. Cases were included in the study if consent for donation of at least one organ was obtained, regardless of whether any organs were actually procured. Data collected for each organ donor included: demographic information; pertinent medical history; etiology of brain injury; medical management requirements; results of organ evaluations, organs consented and procured; and reasons for non-utilization.

An organ donation framework (Figures 1 and 2 ) was established to highlight key areas where organs are lost from the transplantation stream. Organs are not available for transplant when they are not consented and/or not offered to transplant programs, or ultimately, if they are refused by transplant programs. A variety of reasons may account for the loss at each key step. For the purposes of this study, reasons for non-utilization were grouped into: donor characteristics (inability to utilize organ related to characteristics of the donor e.g., malignancy); organ function (inability to utilize organ due to suboptimal measurements of organ function); or logistics (inability to utilize organ due to logistical constraints). It was through this framework that organ donor cases from all sites were analyzed.

All cases for which hearts were consented for donation and not utilized were reviewed by the lead
TABLE I Currently accepted "ideal" lung donor criteria

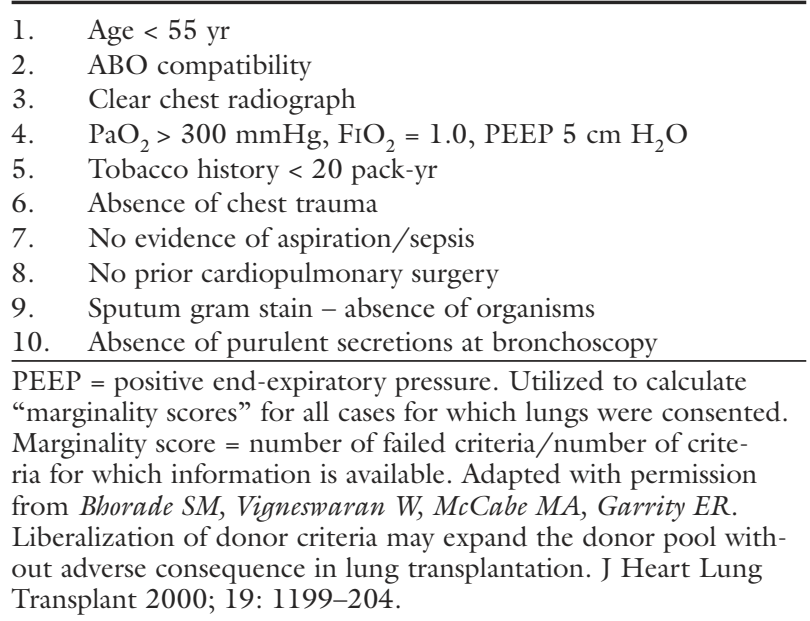

investigator and a study collaborator [both experts in cardiac transplantation (H.R. and V.R)], with application of the Crystal City report cardiac specific recommendations, ${ }^{2}$ to determine whether any alternate management options could have been applied that may have resulted in an increased utilization rate. All cases for which lungs were consented for donation and not utilized were categorized by the study coordinator using the following methodology: a "marginality score" was calculated based on the "currently accepted ideal lung donor" 3 as outlined by Bhorade et al. (Table I). This score was equal to the number of "failed" criteria divided by the number of criteria for which information was available for this donor. Cases of donors with "marginality scores" of 30\% or less were considered moderate to mild and were reviewed by one of the study collaborators [expert in lung transplantation (S.K.)] to determine whether any alternate management options could have been applied (which may have resulted in an increased utilization rate of lungs).

\section{Results}

A summary of the descriptive characteristics of all donors included in the study is shown in Table II. The majority of donors were female and the median age was $47 \mathrm{yr}$. Thirty-two percent of donors had a smoking history of $\geq 20$ pack-yr. Cerebral vascular accidents were the primary cause of brain injury resulting in the neurological determination of death. 
TABLE II Study population

\begin{tabular}{|c|c|c|c|c|c|}
\hline & $\begin{array}{l}\text { Site } 1 \\
(n=15)\end{array}$ & $\begin{array}{l}\text { Site } 2 \\
(n=24)\end{array}$ & $\begin{array}{l}\text { Site } 3 \\
(n=31)\end{array}$ & $\begin{array}{l}\text { Site } 4 \\
(n=53)\end{array}$ & $\begin{array}{c}\text { All centres } \\
(n=123)\end{array}$ \\
\hline \multicolumn{6}{|l|}{ Age (yr) } \\
\hline Range & $38-71$ & $19-55$ & $18-88$ & $18-77$ & $18-88$ \\
\hline \multicolumn{6}{|l|}{ Sex } \\
\hline \multicolumn{6}{|l|}{ Weight (kg) } \\
\hline Median & 75 & 75.8 & 77 & 70 & 72 \\
\hline Range & $50-120$ & $48-140$ & $50-160$ & $40-107$ & $40-160$ \\
\hline \multicolumn{6}{|l|}{ Height* $\left.^{*} \mathrm{~cm}\right)$} \\
\hline Median & 164 & 175 & 170 & 168.5 & 170 \\
\hline$\%$ smokers & $73 \%$ & $75 \%$ & $45 \%$ & $58 \%$ & $60 \%$ \\
\hline$\% \geq 20$ pack-yr & $53 \%$ & $21 \%$ & $35 \%$ & $28 \%$ & $32 \%$ \\
\hline \multicolumn{6}{|l|}{ Blood type } \\
\hline $\mathrm{O}+/-$ & $6 / 0$ & $12 / 3$ & $8 / 1$ & $24 / 3$ & $50 / 7$ \\
\hline $\mathrm{A}+/-$ & $3 / 2$ & $5 / 1$ & $12 / 3$ & $18 / 0$ & $38 / 6$ \\
\hline $\mathrm{B}+/-$ & $3 / 0$ & $3 / 0$ & $0 / 1$ & $3 / 0$ & $9 / 1$ \\
\hline $\mathrm{AB}+/-$ & $1 / 0$ & $0 / 0$ & $3 / 0$ & $2 / 3$ & $6 / 3$ \\
\hline \multicolumn{6}{|l|}{ Brain injury } \\
\hline CVA & $80 \%$ & $33 \%$ & $58 \%$ & $60 \%$ & $57 \%$ \\
\hline Trauma & $13 \%$ & $37.5 \%$ & $39 \%$ & $32 \%$ & $32 \%$ \\
\hline HIE & $7 \%$ & $17 \%$ & $3 \%$ & $8 \%$ & $8 \%$ \\
\hline
\end{tabular}

Utilization rates of hearts and lungs investigated in this study were comparable to Canadian and other published rates. Forty-two hearts were transplanted from 107 donors who were consented for heart donation, resulting in a utilization rate of $39 \%$. This is slightly better than the CORR 2001 Canadian utilization rates ${ }^{1}$ of $35 \%$ for hearts. (It should be noted that CORR only includes donors that had a minimum of one organ transplanted, the present study included donors even if no organs were transplanted). The utilization rate is also comparable with the United Network for Organ Sharing (UNOS) statistics for the year 2002, which found an average donor yield for hearts of $36 \% .^{4}$ (UNOS is mandated in the United States as a non-profit, scientific and educational organization that administers the Organ Procurement and Transplantation Network).
A summary of the hearts reviewed and their outcomes is shown in Figure 1. Of 123 donors who were consented for the use of at least one of their organs, $16(13 \%)$ were not consented for heart donation. Of the 107 consented hearts, 12 (11\%) were not offered out to OPOs/transplant programs. Of the 95 hearts offered, $53(56 \%)$ were refused and therefore not transplanted. A variety of reasons were established for non-offer and non-transplantation. For the hearts not offered, $50 \%(6 / 12)$ were due to organ function, $42 \%(5 / 12)$ were due to donor characteristics and the remaining $8 \%(1 / 12)$ were due to logistical issues. For the hearts offered and refused, 55\% (29/53) were due to organ function, $32 \%(17 / 53)$ were due to donor characteristics and the remaining $13 \%(7 / 53)$ were due to logistical issues. Combining the reasons for non-offer and non-transplantation, 54\% (35/65) 


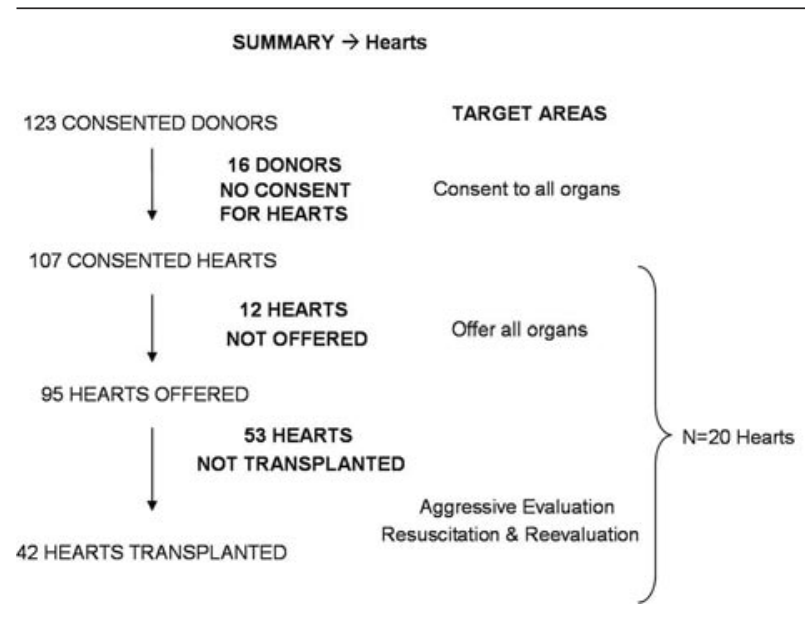

FIGURE I Summary of heart allocation. The number of consented donors, hearts, and allocation of hearts is shown. Key areas where hearts are lost from the organ donation/ transplantation stream are highlighted. Strategies (target areas) that may increase yield of hearts per consented donor are outlined. Explained in detail in text.

of hearts were not used due to organ function, 34\% $(22 / 65)$ due to donor characteristics, and $12 \%(8 / 65)$ due to logistical issues.

Of the 65 hearts that were consented and not utilized, suggestions for alternate management were made in $20(31 \%)$ cases, (four of which were for organs that were not offered out). In nine cases a strategy of organ resuscitation and reevaluation was suggested. In five cases more aggressive offering was suggested (i.e., offer to UNOS or high status recipient). In another five cases more aggressive evaluations were suggested (either an angiogram or echocardiogram should have been performed). In one case it was suggested that the organ should have been reconsidered and possibly accepted even though an angiogram was not available. As a result of this analysis, 20 hearts may have been utilized if alternative management approaches had been followed.

Twenty-five double lungs and four single lungs (total of 54 lungs $/ 29$ donors) were transplanted from 210 consented lungs/105 donors who were consented for lung donation. This resulted in a utilization rate of 26\% (lungs) or 28\% (lung donors). Canadian Organ Replacement Register 2001 Canadian utilizations rates ${ }^{1}$ are comparable with $23 \%$ (lungs) or $28 \%$ (lung donors). In a 2002 study by Pierre et al. only about $20 \%$ of multiorgan donors ultimately have lungs that are suitable for lung transplantation according to

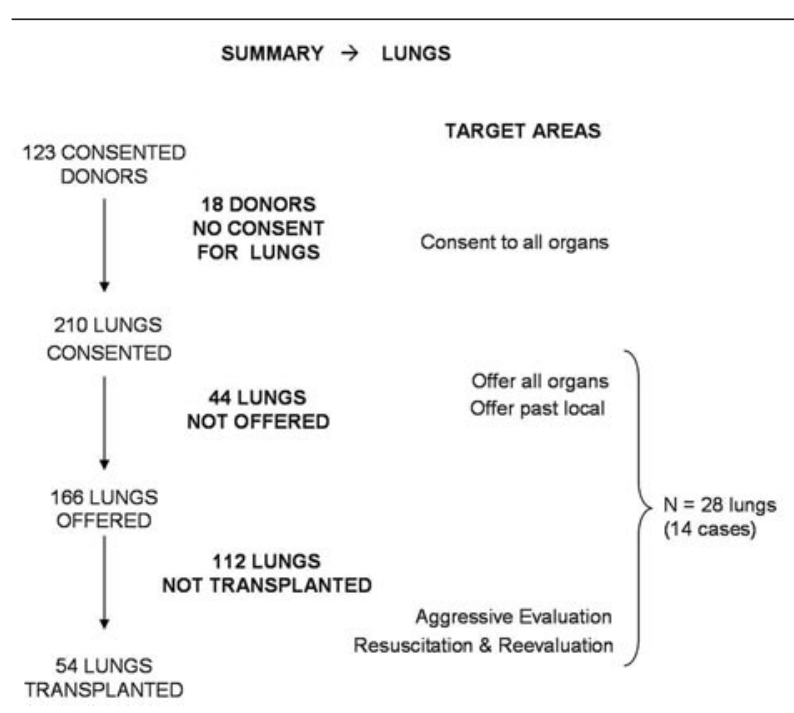

FIGURE 2 Summary of lung allocation. The number of consented donors, lungs, and allocation of lungs is shown. Key areas where lungs are lost from the organ donation/ transplantation stream are highlighted. Strategies (target areas) that may increase yield of lungs per consented donor are outlined. Explained in detail in text.

currently accepted criteria. ${ }^{5}$ Average lung procurement rates in the United States for the year 2002 were $15 \%{ }^{4}$ Australian rates are amongst the highest with lungs being procured from $44 \%$ of deceased donors. ${ }^{6}$

A summary of the lungs reviewed and their outcomes is shown in Figure 2. Of 123 donors who were consented for the use of at least one of their organs, $18(15 \%)$ were not consented for lung donation. Lungs are generally offered as a set, however here they will be reported individually for the sake of clarity. Of the 210 consented lungs, $44(21 \%)$ were not offered out to OPOs/transplant programs. Of the 166 lungs offered, 112 lungs (67\%) were refused and therefore not transplanted. A variety of reasons were established for non-offer and non-transplantation. For the lungs not offered $77 \%(34 / 44)$ were due to organ function, $23 \%(10 / 44)$ were due to donor characteristics. For the lungs offered and refused, $80.4 \%(90 / 112)$ were due to organ function, $14.3 \%(16 / 112)$ were due to donor characteristics, and the remaining 5.3\% $(6 / 112)$ were due to logistical issues. Combining the reasons for non-offer and non-transplantation, 79\% (124/156) of lungs were not used due to organ function, $17 \%(26 / 156)$ due to donor characteristics, and the remaining $4 \%(6 / 156)$ due to logistical issues.

For the 156 lungs that were consented and not utilized, $42(27 \%)$ were categorized as mild to mod- 
erately marginal and reviewed. Alternate management was suggested for 28 of these $42(67 \%)$ lungs (14 cases), (in four of these cases organs were not offered out). In seven cases (14 lungs) a strategy of organ resuscitation and reevaluation was suggested, in three cases (six lungs) more aggressive evaluations and in two cases (four lungs) more aggressive offering (i.e., offer outside local program). In two cases (four lungs) it was suggested that the organs should have been reconsidered and possibly accepted. As a result of this analysis, 28 lungs may have been utilized if alternative management approaches had been followed.

\section{Discussion}

There is a worldwide gap between the supply and demand for transplantable organs, and this gap is enlarging, reaching a crisis level in Canada. Of those patients currently on a heart transplant list approximately $50 \%$ will never receive a transplant. ${ }^{7}$ In Canada in 1999 there was a $21 \%$ increase in the number of patients listed for heart transplant but only a $6 \%$ increase in the number of donors over that same time period resulting in an annual $25 \%$ mortality of patients listed. ${ }^{8}$

Current listing criteria are strict and conservative estimates are that we transplant only 5 to $10 \%$ of those who may benefit. There may be as many as 5,000 patients in Canada age $<65$ who would benefit from a heart transplant, a number that doubles with every five-year increase in age. ${ }^{7}$ Similar results are found when one looks at end stage liver, lung or kidney disease. Improvements in medical therapy continue to reduce disease progression and increase survival for patients with end stage diseases such as congestive heart failure, however, these improvements have not reduced organ transplantation need, only delayed it. Hence it is critical that all potential deceased organ donors are realized.

This study found a utilization rate of $39 \%(42 / 107)$ for heart and 28\% (29/105) for lung donors across four Canadian OPO sites. These utilization rates are comparable with Canadian ${ }^{1}$ and international rates. ${ }^{2,4-6}$ Organ function was the most frequently cited reason for non-utilization, [54\% $(35 / 65)$ of the hearts and 79\% (124/156) of the lungs]. Donor characteristics were cited as reasons for non-utilization in $34 \%(22 / 65)$ of the hearts and $17 \%(26 / 156)$ of the lungs. Logistical issues were the least frequent cause of organ non-utilization [12\% (8/65) and 4\% (6/156) of hearts and lungs respectively]. This study identifies three general target areas for changes in practice that may yield a higher organ utilization rate: consent, offers, and donor management.
In a total of 34 cases ( 16 for hearts and 18 for lungs), donors were consented for some, but not all organs. The issue of consent, how it is done and by whom, is an important one. Procedures for obtaining consent for organ donation vary across the country. Depending upon the model used, consent may be requested by a variety of individuals such as an intensivist, an organ donation resource nurse, an organ donation coordinator (the latter two are in-hospital OPO employees), etc. In every case, it is the OPO employee who is responsible to review the consent form to ensure proper consent is signed prior to proceeding with procurement.

It was not the intent of this study to deal with issues of consent, however this study raises concerns by finding cases in which consent is obtained for the donor but not for the heart/lungs. One could conceive of a scenario in which the family refused consent for the heart given the possible symbolic/emotional interpretations of such a donation. It is much more difficult to envisage such a situation for the lungs. This study did not examine why consent was not obtained for individual organs. It is speculated that the individual obtaining consent or the OPOs may have judged these organs as unsuitable. Consent should be requested for all organs, hence avoiding an a priori decision as to which organs are deemed suitable for transplantation.

The distribution of donated organs falls within the mandate of the provincial OPOs. They are responsible for the offering of organs (according to standardized algorithms) to OPOs/transplant programs within the country and internationally (UNOS). This study found 34 cases ( 12 potential heart donors and 22 potential lung donors) in which organs were consented but not offered out. For the hearts not offered, $50 \%(6 / 12)$ were due to organ function, $42 \%(5 / 12)$ were due to donor characteristics and the remaining $8 \%(1 / 12)$ were due to logistical issues. For the lungs not offered $77 \%(34 / 44)$ were due to organ function, $23 \%(10 / 44)$ were due to donor characteristics.

In these situations it must be assumed that the OPOs judged these organs as unsuitable and decided not to offer them out. However in eight cases (four heart cases and four lung cases) suggestions for alternative management were made which may have resulted in the utilization of these organs. Hence the concern that $24 \%(8 / 34)$ of the cases not offered out to OPOs/transplant programs had the potential to provide transplantable organs.

All consented organs should be offered and then offered widely if initially refused. (This was particularly relevant in the case of lungs; when initially refused by their local program they were rarely offered 
to other programs). Donor/recipient dependence relationships may result in one transplant program utilizing an organ previously refused by a different program. Often the procuring organization does not know specific recipient data that may make a 'marginal' donor become a suitable donor. Although local programs may not have a suitable recipient, specific details on recipients in other locals may be unavailable to the local OPO. The decision of donor suitability for transplantation should be left in the hands of the recipient transplant team. In cases in which a truly marginal organ is used, how each program approaches the recipient is program dependent. Our centre advocates that the recipient be aware of the situation and consent or not to the receipt of a marginal organ.

Suggestions for alternate management such as organ resuscitation and/or reevaluation, which could have resulted in organ utilization, were made in 20 of $65(31 \%)$ hearts and 28 of 156 (18\%) lungs. Detailed donor management approaches can be found in the Canadian Council for Donation and Transplantation recommendations entitled: Medical Management to Optimize Donor Organ Potential. ${ }^{9}$ Through this approach (more aggressive management/time) organs at first assessed as marginal/unacceptable had the potential to improve and thus be utilized. This study found that a more aggressive management approach in combination with consenting and offering all organs, had the potential to increase utilization rates from $39 \%(42 / 107)$ to $58 \%(62 / 107)$ for hearts and from $26 \%(54 / 210)$ to $39 \%(82 / 210)$ for lungs. These estimates do not take into consideration the organs lost to non-consent.

\section{Study limitations}

The study is based on a retrospective chart review and certain assumptions were made when no information was available. If consent/offers were not charted it was assumed that they did not occur. In some cases where consent was not obtained, it was difficult to assess the "usability" of the organ (particularly lungs), in that the management of the donor (now that the lungs were not being used) may have negatively impacted organ function and suitability. In some cases no reasons for refusal were charted and a reason was hypothesized based on available data. Timing of organ refusal also had an impact. For example, when donors were refused for events occurring on the way to, or in the operating room, details pertaining to these events were not always available in the charts.

The retrospective design limited the ability to address donor-recipient dependence relationships. Specifically, information pertaining to recipient need at the time of donor assessment is not addressed. As well, this study is unable to present the true complexity of individual cases (time limitations, number of organs offered, number of offers for each organ, difficulty/ease of organizing evaluations/beds/transplant teams, etc.). Many of these factors negatively impact the ability to offer and place organs.

In conclusion, changes in management of the donor that includes aggressive medical management and consent/offering of all organs have been addressed outside this study. ${ }^{2,3,9}$ However, several areas were identified in this study where incorporating these changes in donor management might have resulted in an increase in transplantable organs. Generally, the idea of organ resuscitation and reevaluation applies to both hearts and lungs. Organs whose function had initially been assessed as marginal or below acceptable standards may have been "rescued" with these changes in approach. Regardless of the changes made in consent, offers or management, it will be imperative to assess the outcomes of recipients who receive 'marginal' organs. Although pressures are great to produce more organs for transplantation and extend donor criteria, these measures will not be judged successful, comparable survival to the current International Society for Heart and Lung Transplantation outcomes, ${ }^{10}$ unless recipient graft survival rates remain excellent.

\section{Acknowledgements}

We gratefully acknowledge the financial support provided by the Canadian Council for Donation and Transplantation enabling this study and the resulting manuscript. We recognize the input of the Canadian Society of Transplantation, the Canadian Critical Care Society and the Canadian Association of Transplantation. We also thank the following OPOs and our contacts for their willingness to participate and support for this project: HOPE Northern Alberta, Yvette Elmquist, Edmonton; OPEN Newfoundland, Max Bishop, St John's; Quebec Transplant, France Quevillon, Quebec City; Trillium Gift of Life Network, Greg Kalyta, Toronto.

\section{References}

1 Badovinac K. Canadian review of organ utilization (1992-2001). Edmonton: The Canadian Council for Donation and Transplantation, 2004 Available from URL; http://www.ccdt.ca/english/publications/background.html\#mm.

2 ZaroffJG, Rosengard BR, Armstrong WF, et al. Maximizing use of organs recovered from the cadaver donor: cardiac recommendations. J Heart Lung Transplant 2002; 21: 1153-60. 
3 Bhorade SM, Vigneswaran W, McCabe MA, Garrity ER. Liberalization of donor criteria may expand the donor pool without adverse consequence in lung transplantation. J Heart Lung Transplant 2000; 19: 1199-204.

4 United Network for Organ Sharing. Deceased organ specific donors by gender. Available from URL; http://www.optn.org/latestData/rptData.asp.

5 Pierre AF, Sekine $\Upsilon$, Hutcheon MA, Waddell TK, Keshavjee SH. Marginal donor lungs: a reassessment. J Thorac Cardiovasc Surg 2002; 123: 421-7.

6 Herbertt K, Russ GR, eds. Australia and New Zealand Organ Donation Registry (ANZOD Registry) 2003 report. Adelaide, South Australia; 2003.

7 Cooper DK, Keogh AM, Brink J, et al. Report of the Xenotransplantation Advisory Committee of the International Society for Heart and Lung Transplantation: the present status of xenotransplantation and its potential role in the treatment of endstage cardiac and pulmonary diseases. J Heart Lung Transplant 2000; 19: 1125-65.

8 Ross H, Hendry P, Dipchand A, et al. 2001 Canadian Cardiovascular Society Consensus Conference on cardiac transplantation. Can J Cardiol 2003; 19: 620-4.

9 Canadian Council for Donation and Transplantation. Medical management to optimize donor organ potential: a Canadian forum, 2004. Available from URL; http://www.ccdt.ca/english/publications/final.html.

10 International Society for Heart and Lung

Transplantation. ISHLT Transplant Registry Quarterly Reports. Available from URL; http://www.ishlt.org/ registries/quarterlyDataReport.asp. 